\title{
Students' Perceptions of Online Physiology Lab Work in Nervous and Musculoskeletal Systems Block
}

\author{
Miranti Dewi Pramaningtyas ${ }^{1 *}$, Titis Nurmasitoh ${ }^{2}$, Rokhima Lusiantari $^{3}$ \\ ${ }^{1}$ Department of Physiology, Faculty of Medicine, Universitas Islam Indonesia, Yogyakarta, Indonesia \\ ${ }^{2}$ Department of Physiology, Faculty of Medicine, Universitas Islam Indonesia, Yogyakarta, Indonesia \\ ${ }^{3}$ Department of Physiology, Faculty of Medicine, Universitas Islam Indonesia, Yogyakarta, Indonesia \\ *Corresponding author. Email: miranti.dewi@uii.ac.id
}

\begin{abstract}
Introduction: The pandemic situation that has been taking place in Indonesia since March 2020 has brought several changes to the learning process in medical faculty. Lab work is one of the online lessons that medical students have to complete. Online lab work carried out by students is expected to be able to achieve the learning goals. The purpose of this study was to determine students' perceptions of the implementation of online lab work.

Methods: This research was an observational study with a cross-sectional design. The samples in this study were all students who participated in the physiology lab work in the nervous and musculoskeletal block. Data were obtained from the lab work evaluation questionnaire.

Results: A total of $91.12 \%$ students have read the materials in the form of videos and guidebooks uploaded through Google Classroom. Students were satisfied with the implementation of lab work $(60.95 \%)$ and considered the video in Google Classroom useful (98.22\%). The percentage of students who agreed that online physiology lab work is important to be carried out synchronously reached $63.31 \%$. Qualitative data showed that some students felt the online lab work helped understand the material. The problem with lab work was that online lab work was less comfortable because students could not practice directly and were constrained by internet signals.

Conclusion: Students' perceptions of online physiology lab work in nervous and musculoskeletal block are considered important and support understanding of the block materials.
\end{abstract}

Keywords: Lab work, Physiology, Online, Perception, Students.

\section{INTRODUCTION}

Learning activities during the Covid-19 pandemic have to continue to run to achieve the predetermined learning goals. Online learning is an option for primary, secondary, and higher education, including the learning process at the Faculty of Medicine. Different learning situations require adaptation from lecturers and students. Before the pandemic, face-to-face learning allowed lecturers and students to interact directly [1]. Changes in learning methods require modification to enable all learning objectives to be achieved optimally [2], and one of them is in the lab work activities in the Department of Physiology.

The Department of Physiology is one of the departments that explores the normal functioning of the body. The understanding of this basic material is highly supportive of the understanding in the clinical phase. Physiology learns homeostasis from all systems that exist in the human body. Lab work activities become one of the learning activities carried out by the Department of Physiology. They are considered as one of the centers of physiology learning since, through these activities, students are expected to gain an optimal understanding of the basic concepts of homeostasis in their body. Motoric and cognitive involvement in lab work activities becomes reinforcement of students' understanding [3]

Before the pandemic, most learning activities were conducted face-to-face. This kind of learning model allows lecturers and students to discuss directly and practice skills well [1]. Physiology lab work conducted online makes the interaction between lecturers, lab work 
assistants, and students greatly reduced. However, the learning objectives still have to be achieved. This condition requires an evaluation related to students' perception of the implementation of online physiology lab work. Evaluation of the students' perception is considered important in the implementation of online lab work because the physiology lab work in the nervous and musculoskeletal system block becomes the first lab work in the first year of physiology department. Besides, the students' perception will influence the motivation for participating in the online lab work as well as the motivation to work on previously shared assignments. Student motivation is essential for the achievement of learning objectives in lab work [3].

In addition to evaluating students' perceptions of the implementation of online physiology lab work, there is also an evaluation of the medium to deliver the lab work materials. The learning media used in the process of distance learning is one of the important components that play a role in the achievement of learning objectives [4].

\section{METHODS}

Physiology lab work in the nervous and musculoskeletal system block is the first lab work of the Physiology Department held for first-year students. In the nervous and musculoskeletal system block, the lab work method applied is the use of videos. Lab work videos are made based on the learning objectives to be achieved. Students can view the videos through Google Classroom before the lab work schedule is implemented. In addition to using videos, the lab work also comes with lab work explanatory slides, assignment cases, and guidebook. The topics of lab work in this block are sensory receptors that include touch receptors, pressure, cold temperatures, and hot temperatures.

All materials for the lab work have been uploaded through Google Classroom as flipped class before the lab work is implemented. Students are given enough opportunities to read and learn all the materials that have been provided. Prior to online lab work, students are assigned to study the lab work materials independently at home. At-home lab work is done using any tools that can be found at home to represent the tools that should be used in the laboratory (props). Students are expected to provide reflecting needles, cold water, hot water, and copper stalks for self-experimentation at home. Such tools are used as a stimulus for smooth touch, sharp touch, cold temperature, and hot temperature. Students are asked to make a $2 \times 2-\mathrm{cm}$ box that is divided into small squares on the skin of the probandus arm with each stimulus given to each small box. Positive results are obtained if the probandus feels a stimulus, then the percentage of the boxes that give a positive result is calculated. The presentation of the results includes a comparison between stimuli.

Synchronous online lab work is implemented using Zoom meeting media. When the synchronous online lab work is performed, the video and the lab work explanation slides are re-posted. Students then discuss the results of at-home lab work with the assistant in the break-out room of Zoom meeting.

After the online lab work is completed, students fill out an online questionnaire about the perception of the implementation of online lab work. The questionnaire consists of 12 yes or no questions, 6 questions with a 1-4 Likert scale, and 4 open questions. The questionnaire shared contains a statement to evaluate how many students have studied the materials in Google Classroom before the lab work, which include videos, guidebook, lab work explanatory slides, and assignment cases. The questionnaire also contains an evaluation of student satisfaction with the course of lab work, which is based on scores and qualitative data. The data obtained is analyzed descriptively to determine the percentage of students who are satisfied or not satisfied with the implementation of online lab work. This data retrieval has been approved by the Ethics Commission of the Faculty of Medicine of Universitas Islam Indonesia.

\section{RESULTS}

A total of 169 students filled out the questionnaire. From the results of the questionnaire that was shared, most students had read all the materials before the lab work was done. Three types of material shared before the lab work, the videos, guidebook, and lab work explanatory slides, were viewed and read by more than $90 \%$ of the students, while the case of assignment was accessed by $76.92 \%$. The result is shown in Table 1 .

Table 1. Number of students who read the materials before the lab work

\begin{tabular}{|l|l|}
\hline Material Type & Number of Students \\
\hline Videotape & $163(96.45 \%)$ \\
\hline Guidebook & $162(95.86 \%)$ \\
\hline Explanatory slide & $161(95.27 \%)$ \\
\hline Assignment case & $130(76.92 \%)$ \\
\hline
\end{tabular}

In terms of satisfaction with the materials shared, the level of student satisfaction reached more than $80 \%$. This result was slightly higher than the number of students who read the materials before the lab work. The result is presented in Table 2.

Table 2. Student Satisfaction Level

\begin{tabular}{|l|c|}
\hline Material Type & Student Satisfaction Level \\
\hline Videotape & 98.22 \\
\hline Guidebook & 97.63 \\
\hline
\end{tabular}




\section{Explanatory slide $\quad 95.86$ \\ \begin{tabular}{l|l} 
Assignment case & 88.76
\end{tabular}}

In general, the percentage of students who were satisfied with the implementation of online physiology lab work on the nervous and musculoskeletal system block was $60.95 \%$. Exactly $63.31 \%$ of the students agreed that lab work is important to be implemented synchronously. Qualitative data on the perception of the implementation of online physiology lab work showed student satisfaction of the discussions with assistants as shown in the following response.

"Fun because the explanation from the assistant is easy to understand"

\section{"It's fun, the assistant is also cool"}

"Fun with laboratory assistants and doctors who explain the material very clearly"

"Feel good because the assistant is nice and relaxing",

Some students felt they were helped by the video provided, and the video was perceived as helping to understand the course of lab work, as shown in the following response.

"There is a lab work video that is very helpful in understanding the lab work material"

The lab work process, in general, was also considered assisting students in understanding lab work as seen in the following response.

"A little confused and troubled moment before lab work, but after lab work I understand better"

Qualitative data showed that the lab work process could make students more aware of the practice materials. Also, lab work and discussion with assistants could strengthen understanding of the materials in the neural and musculoskeletal system block. This is evident in the following response.

"I feel physiology lab work is a complement of the tutorial materials"

"With this lab work, I find it helpful for understanding the materials in block"

The obstacles faced by students during this online lab work were network and internet signal constraints. This is reflected in the following response.

\section{"Signal constraints"}

"It's quite difficult because the influence of the signal also inhibits my complete understanding of the practice"

"It's been good, just sometimes the signal difficulty"

In addition to the constraints in internet network signal, some other students had obstacles because they could not directly use the tools from the laboratory.

"Quite difficult, because we do not practice directly, the limitations of the tools"

\section{DISCUSSION}

The data obtained shows that most students have read the materials shared before the scheduled synchronous online lab work. Video, guidebook, and explanatory slide materials are viewed and read by almost all students $(>90 \%)$. Video is the most viewed material by the students while the case of assignment is seen and read by fewer students. In general, the number of students who read the materials before the lab work indicates high motivation to be well-prepared for the practice of online physiology lab work. Motivation is one of the important factors in the learning process and the achievement of learning objectives. [3]

The lab work video has the largest proportion of views by the students. Materials in the form of videos provide convenience for students to understand the course of lab work. The concept of lab work presented in the video enables students to imagine how the lab work will be implemented [5]. The use of video as a learning tool has been recognized as valuable in learning, making it easier to improve understanding [6]. The availability of this type of materials that supports online learning has a significant impact on students [7].

Students' perception of the implementation of online physiology lab work in the nervous and musculoskeletal system block results in a satisfaction rate of more than $60 \%$. This indicates that most students are satisfied with the implementation of online lab work. Qualitative data shows that this satisfaction is supported by discussions with assistants. Laboratory assistants are seniors who have been specially selected to accompany discussions during lab work. In some learning activities, the presence of assistants from students makes the learning atmosphere more relaxed, thus encouraging interactive discussions [8]. Students feel that discussions with assistants increase their understanding of the practice materials. Interaction with assistants in the break-out room is one of the necessary methods to improve online learning achievements [9]. 
Although in general students feel the online physiology practice goes well, some obstacles remain to be found. Some students are less able to participate optimally in the online lab work due to the internet network signal constraints. An unstable internet network limits students' opportunity to actively participate in discussions during lab work. In the process of online learning, stable quality of internet network is indispensable. Therefore, the government needs to prepare technology that supports this learning process [10].

In addition, the limitations of tools (props) for selfexperimentation at home become one of the obstacles faced by students. Although basically the lab work on this block is quite simple, not all students can provide the simple tools expected, such as reflecting needle and copper stalk. Similar to learning in the skills lab, mannequin or props is one of the components that enable students to learn better than only making observation [11].

\section{CONCLUSION}

The online physiology lab work is one of the learning tools to strengthen the understanding of the block. Therefore, the implementation of online lab work requires some adjustments in order for the learning objectives to be achieved. Students are satisfied with the implementation of physiology lab work in the nervous and musculoskeletal system block which is considered important and supports the content of the block. In addition, the materials in Google Classroom are considered useful and helpful in the implementation of this lab work.

\section{AUTHORS' CONTRIBUTIONS}

MDP: drafting, collecting data, writing manuscripts; TN: drafting, processing data; RLA: drafting

\section{ACKNOWLEDGMENTS}

The authors thank the Faculty of Medicine of Universitas Islam Indonesia for funding this research.

\section{REFERENCES}

[1] Webber-Ritchey KJ, Badowski D, Gibbons L. An Online Asynchronous Physical Assessment Lab (OAPAL) for Graduate Nursing Students Using Low-Fidelity Simulation With Peer Feedback. Nurs Educ Perspect 2020; 41: 378379.

[2] Pather N, Blyth P, Chapman JA, et al. Forced Disruption of Anatomy Education in Australia and New Zealand: An Acute Response to the Covid-19 Pandemic. Anat Sci Educ 2020; 13: 284-300.
[3] Dohn NB, Fago A, Overgaard J, et al. Students motivation toward laboratory work in physiology teaching. Adv Physiol Educ 2016; 40: 313-318.

[4] Simonson M, Schlosser C, Orellana A. Distance education research: A review of the literature. $J$ Comput High Educ 2011; 23: 124-142.

[5] Gu M, Sok SR. Effects of simulation practicum using flipped learning for Korean nursing students. Int J Environ Res Public Health 2020; 17: $1-11$.

[6] Pinsky LE, Wipf JE. A picture is worth a thousand words: Practical use of videotape in teaching. J Gen Intern Med 2000; 15: 805-810.

[7] Chen T, Peng L, Jing B, et al. Analysis of User Satisfaction with Online Education Platforms in China during the COVID-19 Pandemic. Healthcare; 8. Epub ahead of print 2020. DOI: doi.org/10.3390/healthcare8030200.

[8] Bugaj TJ, Blohm M, Schmid C, et al. Peerassisted learning (PAL): Skills lab tutors' experiences and motivation. BMC Med Educ 2019; 19: 1-14.

[9] Sowan AK, Jenkins LS. Designing, delivering and evaluating a distance learning nursing course responsive to students needs. Int J Med Inform 2013; 82: 553-564.

[10] Mishra L, Gupta T, Shree A. Online teachinglearning in higher education during lockdown period of COVID-19 pandemic. Int J Educ Res Open; 1. Epub ahead of print 2020. DOI: https://doi.org/10.1016/j.ijedro.2020.100012.

[11] Upadhayay N. Clinical training in medical students during preclinical years in the skill lab. Adv Med Educ Pract 2017; 8: 189-194. 